\title{
Volatile composition and sensory and quality attributes of quince (Cydonia oblonga Mill.) fruits as affected by water stress
}

\author{
I. Griñán, A. Galindo, P. Rodríguez, D. Morales, M. Corell, A. Centeno \\ J. Collado-González, A. Torrecillas, A.A. Carbonell-Barrachina, F. Hernández
}

\begin{abstract}
A B S T R A C T
No information exists on the effect of water deficit on quince (Cydonia oblonga Mill.) fruit quality characteristics. In this paper, the effect of withholding irrigation water in the middle of the rapid fruit growth period on yield, main fruit physicochemical characteristics, sensory profile, and volatile composition of quince (cv. BA-29) was studied. The linear fruit growth phase was seen to be a critical phenological period for the marketable yield of quince because water deficit decreased the fruit weight, size, and moisture content. Also, this period was clearly critical for the fruit's chemical characteristics. Water deficit induced important changes in an important number of the identified volatile compounds, characterized by decreases on pear, pineapple and apple sensory descriptors and increases on the green-herbaceous sensory descriptors. Moreover, total soluble solids increased and the total polyphenols content and antioxidant activity decreased as a result of water deficit effect, even though the still high levels of total polyphenols, regardless of the fruit water status, suggested that quinces can be used as an important source of natural antioxidants. The fruit sensory analysis indicated that the peel colour intensity of fruits from the water deficit treatment increased and fruit flesh texture improved. Indeed, the main handicaps for its consumption as fresh fruit (corkiness and fibreness) severely decreased and crunchiness increased.
\end{abstract}

\section{Introduction}

The fruit tree industry of the Mediterranean basin is facing several important challenges, which are seriously limiting its profitability. Among them, water is considered the main limiting factor for optimal fruit and vegetable farming, and the availability of this resource is drastically being reduced. In addition, Mediterranean agrosystems are economically restricted to the farming of very few plant species of woody crops (Prescott-Allen and Prescott-Allen, 1990). Most of these are high-yielding species, which contribute to the decline in crop diversity in these agricultural systems (Chivenge et al., 2015), which is fundamental for ecosystem functioning, sustainable agricultural production, and increased food and nutritional security (Thrupp, 2000; Toledo and Burlingame, 2006; Chappell and LaValle, 2011).

It is important to face up to the fact that climate change will inevitably lead to very frequent and severe droughts in the near future, so that modern sustainable agriculture in arid and semiarid agrosystems will have to cope with water scarcity by adopting deficit-irrigation strategies. This type of irrigation will help to minimize the impact of water shortage on crop yield and quality and even enable the diversification of fruit tree culture turning growers' attention to a variety of underused fruit tree crops, which may need low inputs of water, synthetic fertilisers and pesticides. Besides, they yield attractive fruits, rich in nutrients and health-promoting compounds, and so have a huge 
potential for improving nutrition and providing preventive effects against some chronic diseases (Baldermann et al., 2016; Galindo et al., 2018; Rodríguez et al., 2018). These type of vegetables and fruits, grown with deficit-irrigation strategies have been aptly called hydroSOStainables (Noguera-Artiaga et al., 2016; Cano-Lamadrid et al., 2017).

To date, there has been no scientific study on the response of quince (Cydonia oblonga Mill.) trees to water deficit, even though it has the reputation of being a highly drought-tolerant underappreciated fruit tree that does not require intensive maintenance and can to be grown in many warm-temperate and temperate regions of the world. It is a deciduous tree and the sole member of the genus Cydonia in the family Rosaceae, which also contains apples (Malus sp.) and pears (Pyrus sp.). Quince is a native of the foothills of the Caucasus Mountains between Persia and Turkmenistan, where it has been cultivated for thousands of years for its fruit, and in the rest of the world for hundreds of years as a dwarfing rootstock for pears. The consumption of the fresh quince fruit (quinces) is not widespread mainly due to their excessive and aggressive astringency and sourness and also their woodiness. However, the ripe fruit of selected quince cultivars have a pleasant, lasting, and powerful flavour (Szychowski et al., 2014). Nowadays, the most popular quince-based products are marmalade, jam, jelly, cakes, and liquors, these products that are much appreciated in many countries (e.g. a jam called "marmalada" in Portugal, a jelly called "dulce de membrillo" in Spain, and "pigwa" liquor in Poland) (Silva et al., 2005; CarbonellBarrachina et al., 2015).

The beneficial health properties of quinces have been known since ancient times, although recent years have seen an increase in attention because of the scientific studies confirming most of these health benefits. For instance, their high antioxidant capacity and interesting phenolic composition have been linked to their hypoglycemic, anti-inflammatory, anti-carcinogenic, antimicrobial, anti-allergic, and antiulcerative activities (Sharma et al., 2011; Legua et al., 2013; Wojdyło et al., 2013).

Pome fruit growth exhibit a single-sigmoid pattern, with only one period of rapid growth, which is considered a critical phenological period because any water deficit at this time causes a delay in the fruit reaching a marketable fruit size (Domingo et al., 1996; Rodríguez et al., 2018). Indeed, under Mediterranean conditions, the quince rapid fruit growth period coincides with very high values of atmospheric evaporative demand and when water prices increase; all the problems associated with optimizing the effectiveness of the irrigation water available may discourage farmers and ultimately cause land abandonment (Katerji et al., 2008; García-Tejero et al., 2014).

Considering all the above, the aim of the current study was to apply water stress in quince farming, withholding irrigation water in the middle of the rapid fruit growth period and studying the effects of this strategy on yield, the main physicochemical characteristics, sensory profile and volatile composition of quince.

\section{Materials and methods}

\subsection{Experimental conditions, plant material and treatments}

The experiment was performed during the summer 2016 at an orchard located at the experimental field station of the Universidad Miguel Hernández de Elche (Escuela Politécnica Superior de Orihuela), near the city of Orihuela (Spain) $\left(38^{\circ} 4^{\prime} \mathrm{N}, 0^{\circ} 59^{\prime} \mathrm{W}\right)$. The plant material consisted of own rooted adult quince trees (C. oblonga (Mill.)), cv. BA29 , spaced following a $4 \mathrm{~m} \times 5 \mathrm{~m}$ pattern.

The soil is a Xerofluvent (Soil Survey Staff, 2006) with a clay loam texture. Analytical data showed a high lime content $(13.6 \%$ active calcium carbonate), very low organic matter content (0.89\%), low cationic exchange capacity ( 6.98 mequiv. $100 \mathrm{~g}^{-1}$ ), and low available potassium and phosphorus levels. The irrigation water had an electrical conductivity of between 1.4 and $1.6 \mathrm{dS} \mathrm{m}^{-1}$ and a chloride concentration of $71-84 \mathrm{mg} \mathrm{L}^{-1}$. Pest control and fertilization practices were those typically used by the region's farmers, and no weeds were allowed to develop within the orchard.

Wind speed $2 \mathrm{~m}$ above the soil surface, rainfall, solar radiation, air temperature, and air relative humidity were measured using an automatic weather station, placed near the experimental plot. Daily values of crop reference evapotranspiration (ETo) were calculated using the Penman-Monteith equation, and the mean daily air vapour pressure deficit (VPDm) was calculated according to Allen et al. (1998).

Quince tree irrigation was carried out daily and during the night using a drip irrigation system with one lateral pipe per tree row. Control (T0) plants were irrigated using six emitters (each delivering $31 \mathrm{~h}^{-1}$ ) to guarantee non-limiting soil water conditions (105\% ETo during the experimental period). T1 plants were irrigated as T0, except during the middle of linear fruit growth phase (day of the year, DOY, 209-251), when irrigation was withheld. To ensure the recovery of T1 plants, reirrigation was performed at the levels used in T0 from DOY 251 to 291 (end of harvesting period). During the measurements period, total water amounts applied were 374 and $143 \mathrm{~mm}$ for T0 and T1 treatments, respectively. Actual precipitation was considered as part of applied water in $\mathrm{T} 0$ and $\mathrm{T} 1$ plants.

\subsection{Plant water status, fruit weight, size, firmness and colour}

Predawn leaf water potential $\left(\Psi_{\mathrm{pd}}\right)$ was measured in mature leaves located on the south facing side, from the middle third of the tree (two leaves per tree and four trees per treatment), using a pressure chamber (PMS 600-EXP, PMS Instruments Company, Albany, USA), as recommended by Turner (1988).

Quince fruits were harvested on the $17^{\text {th }}$ of October 2016 (DOY 291). The mean weight of marketable fruit was determined according to the weight and number of fruits per box in randomly selected boxes per replicate. Measurements of the polar and equatorial diameters of the fruit were made in 20 fruits per replicate, using a digital calliper. Flesh firmness (FF) was determined as the load needed to break the flesh after removal of the peel on two opposite faces in the equatorial zone, using a penetrometer (model FT-327, Facchini, Alfonsine, Italy), equipped with an $8 \mathrm{~mm}$ cylindrical plunger. For the moisture content, samples were oven-dried at $105^{\circ} \mathrm{C}$ until constant weight (AOAC et al., 2000).

Quince peel colour (4 different measurements at 4 equidistant points on the equatorial region of each fruit) were assessed using a Minolta CR 2000 colourimeter (Osaka, Japan) and the results were expressed in the CIELab system. The mean values for lightness $\left(L^{*}\right)$, redgreenness $\left(a^{*}\right)$, and blue-yellowness $\left(b^{*}\right)$ coordinates for each fruit were reported. In addition, the objective colour was calculated as chromaticity or chroma $\left[C^{*}=\left(a^{* 2}+b^{* 2}\right)^{1 / 2}\right]$ and hue angle $\left[H^{o}=\arctan \left(b^{*} /\right.\right.$ $\left.a^{*}\right)$.

2.3. Fruit total soluble solids, acidity, maturity index, total phenolics and total antioxidant activity

Total soluble solids (TSS) and total acidity (TA) were measured in juice samples according to Rodríguez-Guisado et al., 2009, and the maturity index (MI) was calculated as the ratio between TSS and TA.

Freeze-dried quince extract was used to determine the total phenolic compound (TPC) contents following the Cano-Lamadrid et al., 2016 procedure. Quantification was made with respect to a standard curve of gallic acid and the results are expressed as gallic acid equivalents (GAE), mg $100 \mathrm{~g}^{-1} \mathrm{dw}$.

The antioxidant activity (AA) was evaluated with three different methodologies $\left(\mathrm{ABTS}^{+}, \mathrm{FRAP}\right.$ and DPPH$)$. The $\mathrm{ABTS}^{+}$(2,2-azinobis(3-ethylbenzothiazoline-6-sulfonic acid)) radical cation and ferric-reducing antioxidant power (FRAP) methods were applied according to Re et al. (1999), and Benzie and Strain (1996), respectively. The radical scavenging activity was evaluated using the $\mathrm{DPPH}^{*}$ radical (2,2-diphenyl-1-picrylhydrazyl) method, as described by Brand-Williams et al. 
(1995) with a modification in the reaction time (Nuncio-Jáuregui et al., 2015).

\subsection{Fruit sensory analysis}

Seven trained panellists from the Food Quality and Safety Group of the Universidad Miguel Hernández de Elche, UMH (Alicante, Spain) participated in this study. Each of the panellists had more than $750 \mathrm{~h}$ of testing experience with a variety of food products. For the current study, the panellists received further orientation on fresh and processed quinces.

The evaluation was carried out at the UMH facilities using individual booths with a combination of natural and non-natural (fluorescent) light (70-90 fc) and a temperature of $20 \pm 2{ }^{\circ} \mathrm{C}$ during three different sessions. Samples were evaluated in triplicate and the sampling order for each panellist was randomized.

The quince samples ( 3 slices of fresh quince fruit), were served in odour-free, disposable $100 \mathrm{~mL}$ covered plastic cups. Three slices of quince fruit (approximately 40-50 g; each slice from a different fruit) were served to each panellist; additional samples were available if the panellists requested it. All samples were served at room temperature. Unsalted crackers and distilled water were used to clean the palate between samples.

Three sessions of $2 \mathrm{~h}$ were held for the sample evaluation, and fruits from both treatments (T0 and T1) were assayed in each session. Quince samples were assessed using descriptive sensory analysis. Each panellist had a questionnaire to evaluate the following attributes: colour (peel colour and colour homogeneity), odour (quince, fruity, pineapple, apple and pear), flavour (sourness, sweetness, bitterness, and astringency), aroma (fruity, quince, pineapple, pear, and aftertaste) and texture (hardness, crunchiness, juiciness, graininess and fibreness). The panel developed its own sensory lexicon to describe the quality of quince fruits. The attributes and definitions used for the present study are shown in Table 1. A numerical scale, from 0 to 10 with increments of 0.5 , was used, where 0 represents no intensity and 10 represents extremely strong intensity. Results are reported as the mean value \pm standard error.

\subsection{Volatile aroma compounds analysis}

Volatile compounds were extracted from quince samples using headspace solid phase micro-extraction (HS-SPME). After several preliminary tests to optimize the extraction system, $5 \mathrm{~g}$ of milled quince plus $10 \mathrm{~mL}$ of distilled water were placed into a $50 \mathrm{~mL}$ vial hermetically sealed with a polypropylene cap and a polytetrafluoroethylene (PTFE)/ silicone septum. One microliter of the internal standard (nonanal) was added together with $\mathrm{NaCl}$ and the vial was equilibrated for $15 \mathrm{~min}$ at $40{ }^{\circ} \mathrm{C}$ in a water bath. Then a $50 / 30 \mu \mathrm{m}$ DVB/CAR/PDMS (divinylbenzene/carboxen/polydimethylsiloxane) fibre was exposed to the sample headspace for $50 \mathrm{~min}$ at $40{ }^{\circ} \mathrm{C}$.

Isolation and identification of the volatile compounds were performed using a Shimadzu GC-17 A gas chromatograph coupled to a Shimadzu QP-5050 A mass spectrometer (Shimadzu Corporation, Kyoto, Japan). The GC/MS system was equipped with a TRACSIL Meta. $\times 5$ column $(95 \%$ dimethylpolysiloxane $/ 5 \%$ diphenylpolysiloxane, $60 \mathrm{~m} \times 0.25 \mathrm{~mm}, 0.25 \mu \mathrm{m}$ film thickness; Teknokroma S. Coop. C.Ltd, Barcelona, Spain).

The quantification ( $\mathrm{mg} \mathrm{kg}^{-1}$ dry weight, $\mathrm{dw}$ ) of the volatile compounds was performed on a gas chromatograph, Shimadzu 2010, with a flame ionization detector (FID). The column and chromatographic conditions were those previously reported for the GC-MS analysis. The injector temperature was $200{ }^{\circ} \mathrm{C}$ and nitrogen was used as carrier gas $\left(1 \mathrm{~mL} \mathrm{~min}^{-1}\right)$. The relative abundance was obtained from electronic integration measurements using flame ionization detection (FID). Nonanal was used as internal standard and the areas from all compounds were normalized using its area; this compound was chosen after checking that it was not present in the volatile profiles of the samples under study.

\subsection{Statistical design and analysis}

The design of the experiment was completely randomized with four replications, each replication consisting of three adjacent tree rows, each with five trees. Measurements were taken on the inner tree of the central row of each replicate, which were very similar in appearance, while the other trees served as border trees. Data were analysed using SPSS software (SPPS, 2002). Analysis of variance was performed and mean values were compared at $p<0.05$. Values for each replicate were averaged before the mean and the standard error of each treatment were calculated.

Table 1

Odour, aroma, flavour, mouthfeel, and texture attributes and definitions used in the study.

\begin{tabular}{lll}
\hline Attribute & Definition & Reference (flavour) \\
\hline Peel colour & Colour of the quince fruit peel & Pantone $584 \mathrm{U}=2.0$ \\
Pantone $604 \mathrm{U}=8.0$ & $50 \%$ colour homogeneity $=5.0$ \\
Colour homogeneity & Homogeneity of colour in the quince fruit peel & $80 \%$ colour homogeneity $=8.0$ \\
& & Freshly harvested quinces, cv. Vranja $=6.5$ \\
Quince ID (o-a) $)^{\mathrm{a}}$ & A floral, fresh, and fruity aromatics associated to quince & Hacendado yogurt "Macedonia" $=8.5$ \\
Fruity (o-a) & Fresh, fruity aromatics associated with undefined fruits & Hacendado $100 \%$ pineapple juice $=7.5$ \\
Pineapple (o-a) & Sour, fresh, fruity aromatics associated with ripe pineapple & Hacendado mango-apple nectar $=5.5$ \\
Apple (o) & Sweet, light, fruity, somewhat floral aromatic commonly associated with apple juice and apples & Hacendado pear nectar $=6.5$ \\
Pear (o-a) & Sweet, slightly musty, floral, honey/caramel-like, fruity aromatic associated with ripe pears & $0.05 \%$ Citric acid solution $=3.5$ \\
Sourness & Fundamental taste factor of which citric acid is typical & $0.08 \%$ Citric acid solution $=5.0$ \\
& & $2 \%$ Sucrose solution $=2.0$ \\
Sweetness & Fundamental taste factor of which sucrose is typical & $4 \%$ Sucrose solution $=4.0$ \\
& & $0.020 \%$ Caffeine solution $=3.5$ \\
Bitterness & & $0.035 \%$ Caffeine solution $=5.0$ \\
& Fundamental taste factor of which caffeine or quinine is typical & $0.05 \%$ Alum solution $=2.5$ \\
Astringency & & Fresh unpeeled carrot $=8.5$ \\
Hardness & Dry puckering mouthfeel associated with an alum solution & Fresh unpeeled carrot $=7.5$ \\
Crunchiness & Force required to bite through & Raw peeled carrot $=1.5$ \\
Juiciness & The intensity of audible noise at first chew with molars & Marshmallow $=1.0$ \\
Corkiness & Amount of water released from the sample during chewing & Over-ripe pear, cv. Alejandrina $=6.0$ \\
Graininess & Puffiness of the cross section & Fresh strawberry $=3.0$ \\
Fibreness & Amount of woody particles remaining in the mouth just before swallowing the sample & \\
& Stringy particles (size and amount) &
\end{tabular}

\footnotetext{
a o-a stand for odour and aroma, perception of volatile compounds with the food outside or inside the mouth, respectively.
} 


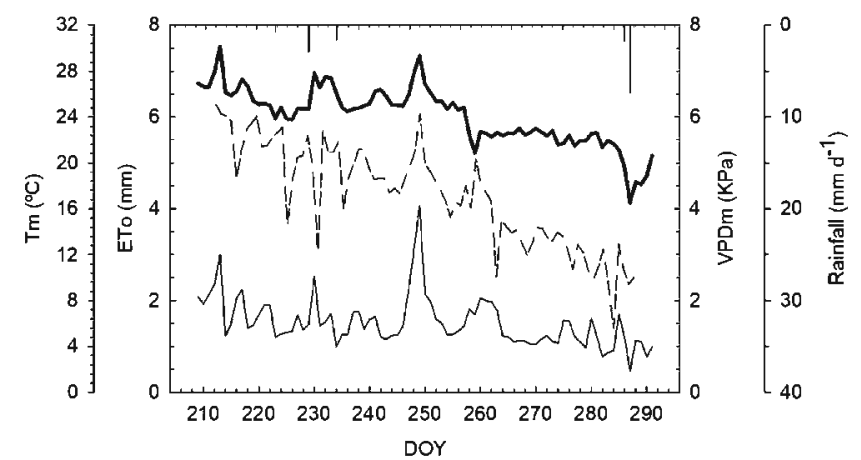

Fig. 1. Daily crop reference evapotranspiration (ETo, medium-medium line), daily mean air temperature ( $\mathrm{Tm}$, solid line), mean daily air vapour pressure deficit (VPDm) (thin line) and daily rainfall (vertical bars) during the experimental period.

\section{Results}

\subsection{Climate, plant water status, yield and fruit physical characteristics}

During the experimental period, the climate was hot and dry [average daily maximum and minimum air temperatures were 31 and $19^{\circ} \mathrm{C}$, respectively; VPDm ranged from 0.46 to $4.06 \mathrm{kPa}$; ETo amounted $357 \mathrm{~mm}$; and, rainfall was $15 \mathrm{~mm}$, mainly on DOY 229 and 287, $10.3 \mathrm{~mm}$ ]. In other words, the climatic characteristics were typically Mediterranean (Fig. 1).

$\Psi_{\text {pd }}$ values for T0 plants were high and almost constant during the experimental period, showing average values of around $-0.48 \mathrm{MPa}$. In contrast, $\Psi_{\mathrm{pd}}$ values for T1 plants gradually decreased from the beginning of the water withholding period, reaching minimum values at the end of the stress period $(-1.27 \mathrm{MPa})$ and recovering to T0 levels when irrigation was resumed (Fig. 2).

The applied water stress decreased fruit weight, size, and moisture content and, as a consequence, the yield of marketable quinces declined (Table 2). However, quince fruits under water stress (T1) showed similar fruit firmness to fruits from fully irrigated tress (T0). A significant effect of water stress on some quince peel colour characteristics was observed (Table 3). In this sense, peel from T1 fruits showed higher $L^{*}$ and $a^{*}$ values and lower $H^{o}$ values than T0 fruits. However, $b^{*}$ and $C^{*}$ values were not statistically affected by the water stress (Table 3 ).

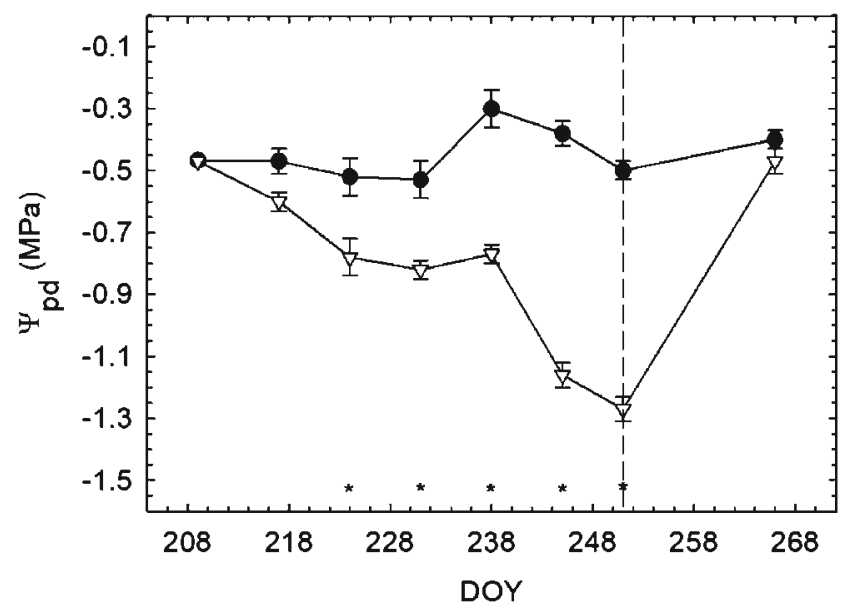

Fig. 2. Predawn leaf water potential $\left(\Psi_{\mathrm{pd}}\right)$ values for quince plants in T0 (closed circles) and T1 (open triangles) treatments during the experimental period. Asterisks indicate significant differences at $p \leq 0.05$.
Table 2

Effect of irrigation treatments on marketable quince yield (MY, $\mathrm{kg}_{\text {tree }}{ }^{-1}$ ), average fruit weight (FW, g), fruit equatorial diameter (ED, $\mathrm{mm}$ ), fruit polar diameter (PD, mm), fruit moisture content (MC, $g$ water $100 \mathrm{~g}^{-1} \mathrm{fw}$ ) and fruit firmness $\left(\mathrm{FF}, \mathrm{kg} \mathrm{cm}^{-2}\right.$ ). Means within a column that do not have a common letter are significantly different at $p \leq 0.05$.

\begin{tabular}{lllllll}
\hline Treatment & MY & FW & ED & PD & MC & FF \\
\hline T0 & $45.97 \mathrm{a}$ & $276.25 \mathrm{a}$ & $82.57 \mathrm{a}$ & $75.45 \mathrm{a}$ & $80.90 \mathrm{a}$ & $6.32 \mathrm{a}$ \\
T1 & $32.38 \mathrm{~b}$ & $227.39 \mathrm{~b}$ & $77.46 \mathrm{~b}$ & $67.58 \mathrm{~b}$ & $78.44 \mathrm{~b}$ & $6.59 \mathrm{a}$ \\
\hline
\end{tabular}

Table 3

Effect of irrigation treatments on quince peel lightness (CIE $L^{*}$ ), red/greenness (CIE $\left.a^{*}\right)$, blue/yellowness (CIE $\left.b^{*}\right)$, chroma $\left(C^{*}\right)$ and hue angle $\left(H^{o}\right)$ values. Values are the mean of 4 replications. Means within a column that do not have a common letter are significantly different at $p \leq 0.05$.

\begin{tabular}{llllll}
\hline Treatment & $L^{*}$ & $a^{*}$ & $b^{*}$ & $C^{*}$ & $H^{o}$ \\
\hline T0 & $73,04 \mathrm{~b}$ & $-1,39 \mathrm{~b}$ & $56,14 \mathrm{a}$ & $56,21 \mathrm{a}$ & $91,46 \mathrm{a}$ \\
T1 & $74,18 \mathrm{a}$ & $-0,36 \mathrm{a}$ & $55,64 \mathrm{a}$ & $55,67 \mathrm{a}$ & $90,38 \mathrm{~b}$ \\
\hline
\end{tabular}

Table 4

Effect of irrigation treatments on flesh quince total soluble solids (TSS, ${ }^{\circ}$ Brix), titrable acidity (TA, $g$ anhydrous malic acid $\mathrm{L}^{-1}$ ), $\mathrm{pH}$ and maturity index (MI, TSS/TA). Values are the mean of 4 replications. Means within a column that do not have a common letter are significantly different at $p \leq 0.05$.

\begin{tabular}{lllll}
\hline Treatment & TSS & TA & pH & MI \\
\hline T0 & $15.7 \mathrm{~b}$ & $5.39 \mathrm{a}$ & $4.2 \mathrm{a}$ & $29.3 \mathrm{a}$ \\
T1 & $17.07 \mathrm{a}$ & $4.67 \mathrm{a}$ & $4.5 \mathrm{a}$ & $37.4 \mathrm{a}$ \\
\hline
\end{tabular}

\subsection{Fruit chemical characteristics}

No significant effect of water stress was observed on $\mathrm{pH}$, TA, and MI (TSS/TA) values. In contrast, the flesh of T1 quince fruits showed a higher TSS value than that of T0 fruits (Table 4). Flesh TPC values in T1 fruits decreased though a water stress effect. However, the levels observed in both treatments, which ranged from 1700 to $1850 \mathrm{mg} \mathrm{GAE}$ $100 \mathrm{~g}^{-1}$, can be considered as very high (Table 5). The response of the AA values, evaluated with three different methodologies (ABTS ${ }^{+}$, FRAP and $\mathrm{DPPH}^{\circ}$ ), to water stress showed different trends. In this way, AA$\mathrm{DPPH}^{*}$ values in T0 and T1 fruits were statistically equivalent; whereas AA-ABTS + and AA-FRAP values in T1 fruits decreased compared to those of T0. However, only $\mathrm{ABTS}^{+}$values correlated with TPC values $\left(\right.$ ABTS $^{+}=33.42+0.007$ TPC, $\left.r^{2}=0.372^{* *}\right)$.

\subsection{Sensory analysis and volatile aroma compounds}

Water deficit significantly affected 11 of the 22 evaluated sensory attributes of quince fruits, which are described in Table 1 . Nine of these sensory attributes increased their intensity as a result of water stress, whereas only 2 of them decreased their values (Fig. 3). One appearance attribute (peel colour), 3 odour notes (fruity, apple, and pear), 2 aroma notes (quince and apple-pear), sourness, crunchiness, and aftertaste

Table 5

Effect of irrigation treatments on flesh quince total polyphenols content (TPC, mg GAE $100 \mathrm{~g}^{-1} \mathrm{dw}$ ) and total antioxidant activity (AA, mmol Trolox kg ${ }^{-1} \mathrm{dw}$ ) measured according to $\mathrm{ABTS}^{+}$, DPPH and FRAP assays. Values are the mean of 4 replications. Means within a column that do not have a common letter are significantly different at $p \leq 0.05$.

\begin{tabular}{lllll}
\hline Treatment & TPC & AA-ABTS $^{+}$ & AA-DPPH & AA-FRAP \\
\hline T0 & $1852.50 \mathrm{a}$ & $46.40 \mathrm{a}$ & $62.64 \mathrm{a}$ & $317.18 \mathrm{a}$ \\
T1 & $1707.39 \mathrm{~b}$ & $44.56 \mathrm{~b}$ & $60.65 \mathrm{a}$ & $252.75 \mathrm{~b}$ \\
\hline
\end{tabular}




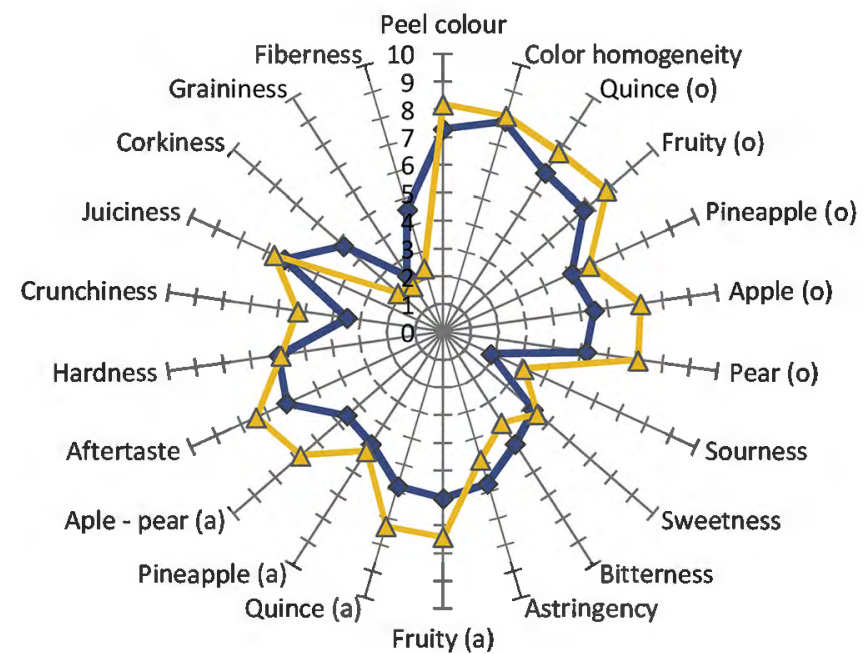

Fig. 3. Descriptive sensory analysis in T0 (blue line) and T1 (yellow line) quince fruits (For interpretation of the references to colour in this figure legend, the reader is referred to the web version of this article).

were higher in the T1 fruits, while 2 undesirable attributes (corkiness and fibreness) decreased their intensity in water stressed fruits (Fig. 3).

The volatile profile of quince fruits was characterized by 54 compounds of 7 chemical families (31 esters, 8 alcohols, 6 terpenes, 4 aldehydes, 3 hydrocarbons, 1 ketone, and 1 phenolic compound) (Table 6). In general, esters were the most abundant compounds followed by terpenes and alcohols (Fig. 4). The water deficit only significantly affected the total alcohols, aldehyde and terpene contents, the first two increasing and the last decreasing (Fig. 4). The most abundant compounds (above $400 \mathrm{mg} \mathrm{kg}^{-1} \mathrm{dw}$ ) in T0 fruits were ethyl octanoate (3366 mg kg ${ }^{-1} \mathrm{dw}$ ), E,E- $\alpha$-farnesene $\left(2853 \mathrm{mg} \mathrm{kg}^{-1} \mathrm{dw}\right.$ ), and ethyl hexanoate $\left(764 \mathrm{mg} \mathrm{kg}^{-1} \mathrm{dw}\right)$, while in T1 fruits the predominant compounds were ethyl octanoate (1739 $\left.\mathrm{mg} \mathrm{kg}^{-1} \mathrm{dw}\right), E, E-\alpha-$ farnesene (1076 mg kg${ }^{-1} \mathrm{dw}$ ), ethyl hexanoate $\left(756 \mathrm{mg} \mathrm{kg}^{-1} \mathrm{dw}\right)$, 1hexanol (496 mg kg-1 $\mathrm{dw})$, and butyl acetate $\left(478 \mathrm{mg} \mathrm{kg}^{-1} \mathrm{dw}\right)$ (Table 6).

Although the volatile profile was similar in quince fruits from both irrigation treatments (the same compounds were found in the quinces from both treatments), water deficit induced important changes in the content of 27 identified compounds out of a total of 55 (Table 6). In fact, in T1 fruits the most important observed changes were increases in the contents of butyl acetate, 1-hexanol, ethyl hexanoate and butyl acetate, and decreases in the contents of ethyl octanoate and E,E- $\alpha$ farnesene.

\section{Discussion}

The fact that $\Psi_{\mathrm{pd}}$ values for T0 plants were high and near constant (Fig. 2) suggested that irrigation water requirements in control quince plants were adequately covered during the experimental period (Fig. 1). In contrast, although the water stress in $\mathrm{T} 1$ plants developed slowly $\left(0.019 \mathrm{MPa} \mathrm{day}^{-1}\right)$, the duration of the water withholding period (42 days) led to a substantial water stress level $\left(\Psi_{\mathrm{pd}}=-1.27 \mathrm{MPa}\right)$ (Fig. 2). When T1 plants recovered, the $\Psi_{\mathrm{pd}}$ values rapidly increased $\left(0.053 \mathrm{MPa} \mathrm{day}^{-1}\right)$, as has been observed in other fruit trees subjected to a strong water stress (Cruz et al., 2012; Mellisho et al., 2012; Galindo et al., 2016).

The water deficit achieved in T1 plants during the middle of the linear fruit growth phase indicated that this is a critical period for the quince marketable yield. This decrease in marketable yield (kg fruit/ tree) was mainly due to decreased fruit size. Accepting that there is a direct relation between fruit turgor and growth, it is assumed that during the water stress period, T1 fruits lost turgor with a subsequent decrease in the fruit growth rate, which made it difficult for the full fruit size to be recovered when irrigation was restarted (Dell'Amico et al., 2012; Galindo et al., 2016, 2018; Rodríguez et al., 2018).

Several authors have observed that when the moisture content decreases, for example in jujube or plum fruits, fruit firmness increased as a consequence of a gummy and cork-like jujube flesh structure (Wu et al., 2012) or stiff plum flesh (Salvador et al., 2003). However, quince fruit firmness did not change despite the decrease in fruit moisture content, probably because this decrease in fruit moisture in T1 fruits was not strong enough to cause severe change or damage in quince flesh structure.

The high content of TPC in fruits from both irrigation treatments (Table 5) suggested that quinces, regardless of the fruit water status, can be used as an important source of natural antioxidants. This was even more interesting considering that quince fruits were harvested at commercial ripening (and can thus be considered as fully ripe), and that, according to Remorini et al. (2008), a decrease in TPC is a characteristic of the progress of ripening in fruits, and can be attributed to changes such as hydrolysis of glycosides, the oxidation of phenols by polyphenol oxidases and polymerization of free phenols.

The antioxidant capacity of quince flesh extracts was assessed using $\mathrm{ABTS}^{+}, \mathrm{DPPH}^{\circ}$, and FRAP assays to evaluate the different modes of action of antioxidants (Prior and Cao, 1999; Huang et al., 2005). In this sense, the significant correlation between $\mathrm{AA}-\mathrm{ABTS}^{+}$and TPC values indicated that TPC content determine the AA-ABTS ${ }^{+}$levels (Table 5), whereas FRAP changes by water deficit effect were not directly mediated by TPC changes in this particular vegetal material. In addition, the constancy of AA-DPPH in response to water stress could be due to the fact that this test only considers lipophilic AA (Kuskoski et al., 2005), and is less sensitive than AA-ABTS ${ }^{+}$and AA-FRAP for measuring antioxidant defences (Redha et al., 2014).

In accordance with the quince fruit sensory analysis, the perceived increase in peel colour intensity (fruits were less green) in in the middle of linear fruit growth phase could be used as a tool to improve T1 quinces (Fig. 3) agreed with the instrumental colour data, and, more precisely, with data on the green-red coordinate, $a^{*}$ (Table 3 ). Regarding the texture attributes, it is important to underline that corkiness and fibreness in $\mathrm{T} 1$ quince fruits decreased by around 50\%, whereas crunchiness increased (Fig. 3). Thus, water stress improved quince texture, because fruit corkiness and fibreness are two of the main handicaps for its consumption as fresh fruit (Szychowski et al., 2014).

According to the volatile profile of quince fruits (Table 6), the high number of compounds identified confirmed the high odour and aroma intensity of these fruits. Water deficit induced important changes in an important number of these identified volatile compounds (Table 6). These changes were characterized by decreases in the contents of ethyl octanoate and $E, E$ - $\alpha$-farnesene, which have pear, pineapple and apple sensory descriptors and increases in butyl acetate (banana), 1-hexanol (herbaceous) and ethyl hexanoate (apple and pineapple). An important fact is that even though the two most abundant compounds were found in $\mathrm{T} 0$, there were five compounds above $400 \mathrm{mg} \mathrm{kg}^{-1} \mathrm{dw}$ in $\mathrm{T} 1$ quinces as compared to only 3 in T0 samples.

\section{Conclusions}

The linear fruit growth phase was seen to be a critical phenological period in quince because withholding irrigation water in the middle of this period decreased the fruit weight, size and moisture content, and, as a consequence, marketable yield. In addition, this period was also clearly critical for the chemical characteristics of quince fruit because water deficit leads to important changes in most of the volatile compounds identified, increasing the total soluble solids content and total polyphenolic content and decreasing antioxidant activity. The high levels of total polyphenolics, regardless of the fruit water status, suggested that quinces can be used as an important source of natural antioxidants. Moreover, the fruit sensory analysis indicated that water 
Table 6

Volatile compounds (mg kg ${ }^{-1}$ dry weight, dw) and descriptors (SAFC, 2014) of quince fruits as affected by irrigation treatments.

\begin{tabular}{|c|c|c|c|c|c|c|c|}
\hline \multirow[t]{2}{*}{ Compound } & \multirow[t]{2}{*}{ Chemical family } & \multicolumn{2}{|c|}{ Retention index } & \multirow[t]{2}{*}{ Descriptors } & \multirow[b]{2}{*}{ ANOVA } & \multicolumn{2}{|c|}{$\begin{array}{l}\text { Concentration } \\
\left(\mathrm{mg} \mathrm{kg}^{-1} \mathrm{dw}\right)\end{array}$} \\
\hline & & Exp & Lit & & & T0 & $\mathrm{T} 1$ \\
\hline Ethyl acetate & Ester & 706 & & Anise; pineapple & $* \mathrm{a}$ & $37.7 a^{c}$ & $5.1 \mathrm{~b}$ \\
\hline Ethyl propanoate & Ester & 748 & & & $* *$ & $35.1 \mathrm{a}$ & $6.5 b$ \\
\hline Propyl acetate & Ester & 751 & 695 & Celery; pear & NS & 14.7 & 4.6 \\
\hline Ethyl isobutyrate & Ester & 779 & 738 & Citrus; strawberry & NS & 7.9 & 5.6 \\
\hline 2-Methyl-1-butanol & Alcohol & 782 & 730 & Onion & $* *$ & $68.1 \mathrm{~b}$ & $101 \mathrm{a}$ \\
\hline 2-Methyl-2-butenal & Aldehyde & 787 & 722 & Green, fruity & NS & 19.9 & 16.7 \\
\hline Isobutyl acetate & Ester & 793 & 743 & Apple; banana & NS & 7.3 & 3.2 \\
\hline 2-Methyl-2-buten-1-ol & Alcohol & 811 & 766 & Herbaceous & NS & 13.1 & 17.6 \\
\hline Ethyl butyrate & Ester & 814 & 774 & Banana; pineapple & $*$ & $71.7 \mathrm{a}$ & $40.4 \mathrm{~b}$ \\
\hline Butyl acetate & Ester & 829 & 786 & Banana; green & $* * *$ & $214 b$ & $478 \mathrm{a}$ \\
\hline Ethyl 2-methylbutyrate ${ }^{\mathrm{b}}$ & Ester & 862 & 835 & Apple; green; plum & $*$ & $138 \mathrm{a}$ & $53.3 \mathrm{~b}$ \\
\hline Ethyl crotanoate $=$ Ethyl 2-butenoate & Ester & 866 & 819 & & NS & 23.6 & 13.5 \\
\hline Isoamyl acetate & Ester & 899 & 850 & Banana; pear; sweet & $*$ & $241 b$ & $297 a$ \\
\hline t-2-Hexenal & Aldehyde & 901 & 845 & Almond, vegetable & $* * *$ & $33 b$ & $137 \mathrm{a}$ \\
\hline 1-Hexanol & Alcohol & 908 & 860 & Green, herbaceous & $* * *$ & $146 b$ & 496 \\
\hline Amyl acetate & Ester & 933 & 880 & Banana; earthy & NS & 6.3 & 11.6 \\
\hline Prenyl acetate & & 940 & 895 & Apple; lavender & NS & 57.6 & 48.2 \\
\hline$\alpha$-Pinene & Terpene & 942 & 903 & Woody & $*$ & $17.3 \mathrm{~b}$ & $38 \mathrm{a}$ \\
\hline Ethyl tiglate & Ester & 960 & 919 & Caramel; fruity & $*$ & $435 a$ & $246 b$ \\
\hline Ethyl hex-4-enoate ${ }^{\mathrm{b}}$ & Ester & 1008 & 979 & & NS & 40.3 & 35.7 \\
\hline 1-Heptanol & Alcohol & 1009 & 957 & Green, nutty, citrus & $* *$ & $9.9 b$ & $19 \mathrm{a}$ \\
\hline Ethyl hexanoate & Ester & 1016 & 979 & Apple, pineapple & $*$ & $764 b$ & $756 a$ \\
\hline 6-Methyl-5-hepten-2-one & Ketone & 1024 & 972 & Green; oily & NS & 16.8 & 13.9 \\
\hline (Z)-3-Hexenyl acetate & Ester & 1028 & 987 & Banana; vegetable & * & $71.7 \mathrm{~b}$ & $80.7 \mathrm{a}$ \\
\hline Hexyl acetate & Ester & 1032 & 991 & Fruity; apple; floral & $* *$ & $138 b$ & $218 a$ \\
\hline Octanal & Aldehyde & 1038 & 982 & Honey; fruity; citrus & NS & 23.6 & 21.8 \\
\hline Limonene & Terpene & 1041 & 1009 & Lemon, orange & $* * *$ & $43.5 \mathrm{~b}$ & $288 \mathrm{a}$ \\
\hline Propyl tiglate & Ester & 1058 & 1020 & & NS & 17.3 & 13.5 \\
\hline 2-Ethyl-1-hexanol & Alcohol & 1068 & 1016 & Rose & NS & 28.8 & 30.6 \\
\hline Benzenemethanol & Phenolic compound & 1108 & 1053 & Berry, cherry, citrus & NS & 22 & 16.7 \\
\hline 1-Octanol & Alcohol & 1111 & 1060 & Orange; floral & NS & 40.3 & 39 \\
\hline Ethyl heptanoate & Ester & 1116 & 1080 & Berry; pineapple & $*$ & $141 b$ & $178 \mathrm{a}$ \\
\hline IS $=$ NONANAL & Aldehyde & 1141 & 1087 & & NS & & \\
\hline Methyl octanoate & Ester & 1144 & 1105 & Green; citrus; fruity & $* *$ & $105 b$ & $148 \mathrm{a}$ \\
\hline Ethyl 3-hydroxyhexanoate & Ester & 1178 & 1106 & grape; smoky; citrus & NS & 11 & 0.5 \\
\hline Benzyl acetate & Ester & 1207 & 1159 & Fruity; floral; sweet & NS & 41.9 & 44.1 \\
\hline Ethyl (Z)-4-octenoate +1 -Nonanol & & 1212 & 1170 & & $*$ & $273 b$ & $279 a$ \\
\hline Ethyl octanoate & Ester & 1216 & 1176 & Fruity; apricot; floral & $* * *$ & $3366 a$ & $1739 b$ \\
\hline Decanal & Aldehyde & 1244 & 1184 & Floral; citrus; sweet & NS & 13.6 & 13.9 \\
\hline Ethyl-(E)-2-octenoate & Ester & 1274 & 1225 & & NS & 29.3 & 20.9 \\
\hline Tetradecane & hydrocarbon & 1275 & 1300 & & NS & 36.1 & 21.8 \\
\hline 1,2-Benzisothiazole & & 1286 & 1221 & & NS & 48.7 & 34.3 \\
\hline Propyl octanoate & Ester & 1313 & 1277 & & $*$ & $51.8 \mathrm{a}$ & $22.3 \mathrm{~b}$ \\
\hline$\alpha$-Copaene & hydrocarbon & 1395 & 1359 & & NS & 38.2 & 27.4 \\
\hline Ethyl (E)-4-decenoate & Ester & 1402 & 1361 & & NS & 14.1 & 7.4 \\
\hline Ethyl (Z)-4-decenoate & Ester & 1411 & 1361 & & NS & 22.5 & 6.5 \\
\hline Ethyl decanoate & Ester & 1415 & 1378 & Grape; oily; pear & $* *$ & $149 a$ & $39.9 b$ \\
\hline$\beta$-Caryophyllene & Terpene & 1451 & 1409 & Spicy; woody & NS & 51.3 & 40.8 \\
\hline E,E- $\alpha$-Farnesene & Terpene & 1517 & 1485 & & $* * *$ & $2853 a$ & $1076 b$ \\
\hline Elemene & Terpene & 1531 & 1494 & & NS & 18.8 & 18.1 \\
\hline$\Delta$-Cadinene & hydrocarbon & 1539 & 1504 & & NS & 111 & 86.7 \\
\hline (Z,Z)- $\alpha$-Farnesene & Terpene & 1541 & 1500 & Apple, fruity & NS & 33 & 25.5 \\
\hline Ethyl (E)-9-dodecenoate ${ }^{\mathrm{b}}$ & Ester & 1595 & & & $*$ & $119 a$ & $41.7 \mathrm{~b}$ \\
\hline Ethyl (Z)-4-decenoate ${ }^{\mathrm{b}}$ & Ester & 1608 & & & * & $105 a$ & $41.7 \mathrm{~b}$ \\
\hline Ethyl dodecanoate & Ester & 1615 & 1578 & Floral, fruity & * & $101 \mathrm{a}$ & $36.2 \mathrm{~b}$ \\
\hline TOTAL & & & & & & 10538a & $7503 b$ \\
\hline
\end{tabular}

${ }^{\text {a }} \mathrm{NS}=$ not significant at $\mathrm{p} \leq 0.05 ; *$,**, and $* * *$, significant at $\mathrm{p} \leq 0.05,0.01$, and 0.001 , respectively.

b Tentatively identified (only identified by retention indexes and NIST spectral database, 2000).

c Values followed by the same letter, within the same row, were not significantly different $(\mathrm{p} \leq 0.05)$.

deficit during fruit growth increases peel colour intensity and improves fruit flesh texture because the main drawbacks for its consumption as fresh fruit (corkiness and fibreness) severely decreased, whereas crunchiness increased.

\section{Acknowledgements}

We aregrateful to the Ministerio de Economía y Competitividad (MINECO) for funding this research through the project AGL2016-
75794-C4-1-R. IG is a predoctoral student at the Miguel Hernández University. AG and JC-G acknowledge the postdoctoral financial support received from the Ramón Areces Fondation and Juan de la Cierva Program, respectively. This work is the result of the internships of PR and DM (19925/IV/15 and 20127/IV/17) funded by the Seneca Foundation-Agency for Science and Technology in the Region of Murcia under the Jiménez de la Espada Program for Mobility, Cooperation and Internationalization. 


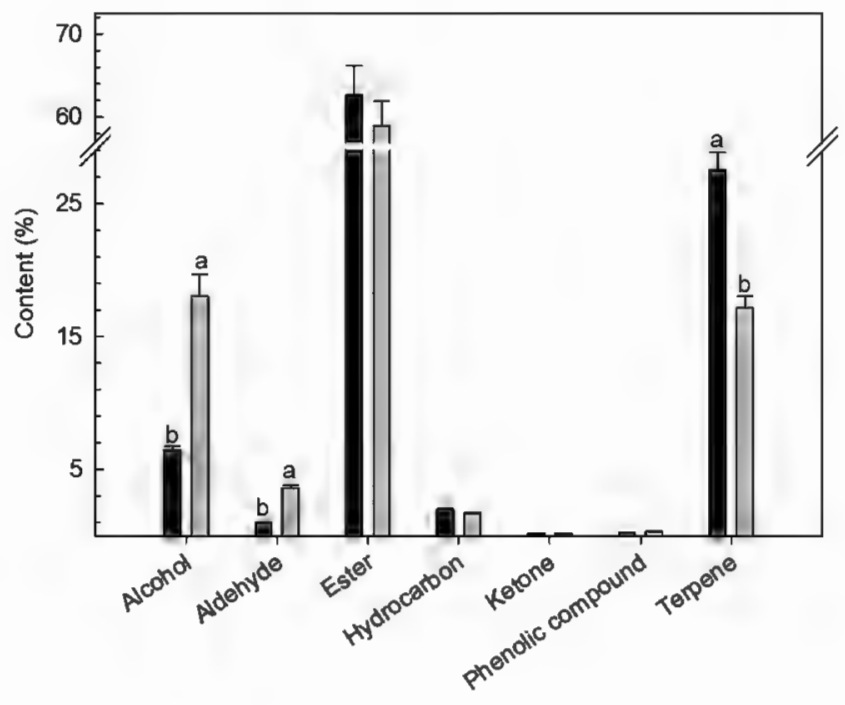

Fig. 4. Chemical families of the volatile compounds (results from Table 6) in T0 (black bars) and T1 (gray bars) quince fruits. Bars for a compound with different letters indicate significant differences at $p \leq 0.05$.

\section{References}

Allen, R.G., Pereira, R.S., Raes, D., Smith, M., 1998. Crop evapotranspiration: guidelines for computing crop water requirements. Irrigation and Drainage. FAO, Italy, Rome Paper 56.

AOAC, 2000. Official Methods of Analysis of AOAC International, 17th ed. AOAC, Gaithersburg, MD, USA.

Baldermann, S., Blagojević, L., Frede, K., Klopsch, R., Neugart, S., Neumann, A., Ngwene, B., Norkeweit, J., Schröter, D., Schröter, A., Schweigert, F.J., Wiesner, M., Schreiner, M., 2016. Are neglected plants the food for the future? Crit. Rev. Plant. Sci. 35, $106-119$.

Benzie, I.F.F., Strain, J., 1996. The ferric reducing ability of plasma (FRAP) as a measure of "antioxidant power": the FRAP assay. Anal. Biochem. 239, 70-76.

Brand-Williams, W., Cuvelier, M.E., Berset, C., 1995. Use of free radical method to evaluate antioxidant activity. Lebensm. Wiss. Technol. 28, 25-30.

Cano-Lamadrid, M., Marhuenda-Egea, F.C., Hernández, F., Rosas-Burgos, E.C., BurgosHernández, A., Carbonell-Barrachina, A.A., 2016. Biological activity of conventional and organic pomegranate juices: antioxidant and antimutagenic potential. Plant. Foods Hum. Nutr. 71, 375-380.

Cano-Lamadrid, M., Hernández, F., Corell, M., Burló, F., Moriana, A., CarbonellBarrachina, A.A., 2017. Antioxidant capacity, fatty acids profile, and descriptive sensory analysis of table olives as affected by deficit irrigation. J. Sci. Food Agric. 97, 444-451.

Carbonell-Barrachina, A.A., Szychowski, P.J., Vásquez, M.V., Hernández, F., Wojdylo, A., 2015. Technological aspects as the main impact on quality of quince liquors. Food Chem. 167, 387-395.

Chappell, M.J., LaValle, L.A., 2011. Food security and biodiversity: can we have both? An agroecological analysis. Agric. Hum. Values 28, 3-26.

Chivenge, P., Mabhaudhi, T., Modi, A.T., Mafongoya, P., 2015. The potential role of neglected and underutilised crop species as future crops under water scarce conditions in sub-Saharan Africa. Int. J. Environ. Res. Publ. Health 12, 5685-5711.

Cruz, Z.N., Rodríguez, P., Galindo, A., Torrecillas, E., Ondoño, S., Mellisho, C.D. Torrecillas, A., 2012. Leaf mechanisms for drought resistance in Zizyphus jujuba trees. Plant. Sci. 197, 77-83.

Dell'Amico, J., Moriana, A., Corell, M., Girón, I.F., Morales, D., Torrecillas, A., Moreno, F., 2012. Low water stress conditions in table olive trees (Olea europaea L.) during pit hardening produced a different response of fruit and leaf water relations. Agric. Water Manage. 114, 11-17.

Domingo, R., Ruiz-Sánchez, M.C., Sánchez-Blanco, M.J., Torrecillas, A., 1996. Water relations, growth and yield of Fino lemon trees under regulated deficit irrigation. Irrig. Sci. $16,115-123$.

Galindo, A., Cruz, Z.N., Rodríguez, P., Collado-González, J., Corell, M., Memmi, H., Moreno, F., Moriana, A., Torrecillas, A., Pérez-López, D., 2016. Jujube fruit water relations at fruit maturation in response to water deficits. Agric. Water Manage. 164, $110-117$.
Galindo, A., Collado-González, J., Griñán, I., Corell, M., Centeno, A., Martín-Palomo, M.J., Girón, I.F., Rodríguez, P., Cruz, Z.N., Memmi, H., Carbonell-Barrachina, A.A., Hernández, F., Torrecillas, A., Moriana, A., López-Pérez, D., 2018. Deficit irrigation and emerging fruit crops as a strategy to save water in Mediterranean semiarid agrosystems. Agric. Water Manage. 202, 311-324.

García-Tejero, I.F., Durán-Zuazo, V.H., Muriel-Fernández, J.L., 2014. Towards sustainable irrigated Mediterranean agriculture: implications for water conservation in semi-arid environments. Water Int. 39, 635-648.

Huang, D., Ou, B., Prior, R.L., 2005. The chemistry behind antioxidant capacity assays. J. Agric. Food Chem. 53, 1841-1856.

Katerji, N., Mastrorilli, M., Rana, G., 2008. Water use efficiency of crops cultivated in the Mediterranean region: review and analysis. Eur. J. Agron. 28, 493-507.

Kuskoski, E., Asuero, A., Troncoso, A., Mancini-Filho, J., Fett, R., 2005. Aplicación de diversos métodos químicos para determinar actividad antioxidante en pulpa de frutos. Food Sci. Technol. (Campinas) 25, 726-732.

Legua, P., Serrano, M., Melgarejo, P., Valero, D., Martínez, J.J., Martínez, R., Hernández, F., 2013. Quality parameters, biocompounds and antioxidant activity in fruits of nine quince (Cydonia oblonga Miller) accessions. Sci. Hortic. 154, 61-65.

Mellisho, C.D., Egea, I., Galindo, A., Rodríguez, P., Rodríguez, J., Conejero, W., Romojaro, F., Torrecillas, A., 2012. Pomegranate (Punica granatum L.) fruit response to different deficit irrigation conditions. Agric. Water Manage. 114, 30-36.

Noguera-Artiaga, L., Lipan, L., Vázquez-Araújo, L., Barber, X., Pérez-López, D., CarbonellBarrachina, A.A., 2016. Opinion of Spanish consumers on hydrosustainable pistachios. J. Food Sci. 81, 2559-2565.

Nuncio-Jáuregui, N., Munera-Picazo, S., Calín-Sánchez, A., Wojdyło, A., Hernández, F., Carbonell-Barrachina, A.A., 2015. Bioactive compound composition of pomegranate fruits removed during thinning. J. Food Compost. Anal. 37, 11-19.

Prescott-Allen, R., Prescott-Allen, C., 1990. How many plants feed the world? Conserv. Biol. 4, 365-374.

Prior, R.L., Cao, G., 1999. In vivo total antioxidant capacity: comparison of different analytical methods. Free Radic. Biol. Med. 27, 1173-1181.

Re, R., Pellegrini, N., Proteggente, A., Pannala, A., Yang, M., Rice-Evans, C., 1999. Antioxidant activity applying an improved ABTS radical cation decolorization assay. Free Radic. Biol. Med. 26, 1231-1237.

Redha, A., Al-Hasan, R., Afzal, M., 2014. Modulation of micronutrients and antioxidants defenses in Conocarpus lancifolius under abiotic stress. J. Food Agric. Environ. 12, 312-319.

Remorini, D., Tavarini, S., Degl'Innocenti, E., Loreti, F., Massai, R., Guidi, L., 2008. Effect of rootstocks and harvesting time on the nutritional quality of peel and flesh of peach fruits. Food Chem. 110, 361-367.

Rodríguez, P., Galindo, A., Collado-González, J., Medina, S., Corell, M., Memmi, H., Girón, I.F., Centeno, A., Martín-Palomo, M.J., Cruz, Z.N., Carbonell-Barrachina, A.A., Hernandez, F., Torrecillas, A., Moriana, A., Pérez-López, D., 2018. Fruit response to water-scarcity scenarios. Water relations and biochemical changes. In: García-Tejero, I.F., Durán, V.H. (Eds.), Water Scarcity and Sustainable Agriculture in Semiarid Environment: Tools, Strategies and Challenges for Woody Crops. Elsevier-Academic Press, pp. 349-375.

Rodríguez-Guisado, I., Hernández, F., Melgarejo, P., Legua, P., Martínez, R., Martínez, J.J., 2009. Chemical, morphological and organoleptical characterisation of five Spanish quince tree clones (Cydonia oblonga Miller). Sci. Hortic. 122, 491-496.

Salvador, A., Cuquerella, J., Martinez-Jávega, J.M., 2003. 1-MCP treatment prolongs postharvest life of 'Santa Rosa' plums. J. Food Sci. 68, 1504-1510.

Sharma, R., Joshi, V.K., Rana, J.C., 2011. Nutritional composition and processed products of quince (Cydonia oblonga Mill.). Indian J. Nat. Prod. Resour. 2, 354-357.

Silva, B.M., Andrade, P.B., Martins, R.C., Valentão, P., Ferreres, F., Seabra, R.M., Ferreira, M.A., 2005. Quince (Cydonia oblonga Miller) fruit characterization using principal component analysis. J. Agric. Food Chem. 53, 111-122.

Soil Survey Staff, 2006. Keys to Soil Taxonomy, 10th edn. USDA-Natural Resources Conservation Service, Washington, DC.

Szychowski, P.J., Munera-Picazo, S., Szumny, A., Carbonell-Barrachina, A.A., Hernández, F., 2014. Quality parameters, bio-compounds, antioxidant activity and sensory attributes of Spanish quinces (Cydonia oblonga Miller). Sci. Hortic. 165, 163-170.

Thrupp, L.A., 2000. Linking agricultural biodiversity and food security: the valuable role of agrobiodiversity for sustainable agriculture. Int. Aff. 76, 283-297.

Toledo, Á., Burlingame, B., 2006. Biodiversity and nutrition: a common path toward global food security and sustainable development. J. Food Compost. Anal. 19, 477-483.

Turner, N.C., 1988. Measurement of plant water status by the pressure chamber technique. Irrig. Sci. 9, 289-308.

Wojdyło, A., Oszmianski, J., Teleszko, M., Sokół-Łetowska, A., 2013. Composition and quantification of major polyphenolic compounds, antioxidant activity and colour properties of quince and mixed quince jams. Int. J. Food Sci. Nutr. 64, 749-756.

Wu, C.S., Gao, Q.H., Guo, X.D., Yu, J.G., Wang, M., 2012. Effect of ripening stage on physicochemical properties and antioxidant profiles of a promising table fruit "pearjujube" (Zizyphus jujuba Mill.). Sci. Hortic. 148, 177-184. 